\title{
Discurso, história e memória a partir do post "vende-se um filhote de bandido"
}

\author{
Discourse, history and memory starting with the post "sells a bandit pup"
}

\author{
Raquel Costa Guimarães Nascimento ${ }^{1}$ \\ Universidade Federal de Goiás - Regional Catalão - UFG \\ raquelcostaguimares@gmail.com
}

\author{
Antônio Fernandes Júnior ${ }^{2}$ \\ Universidade Federal de Goiás - Regional Catalão - UFG \\ tonyfer@uol.com.br
}

\begin{abstract}
RESUMO: Este artigo tem como tema a discussão a respeito de uma publicação feita no Facebook, em 2016, conhecida como "vende-se um filhote de bandido". Abordamos o corpus com base na Análise de Discurso pecheutiana, observando os conceitos:ideologia, interdiscurso, memória e efeitos de sentido. O objetivo foi traçar uma análise sobre o discurso produzido, as circunstâncias que possibilitaram seu aparecimento, bem como suas possibilidades de efeitos de sentido. Os enunciados da referida postagem foram destacados e relacionados a outros, coletados na mídia e em outras plataformas de publicação, de modo a perceber como os discursos anteriores foram recuperados de outras formações discursivas e realocados no post, sem, contudo, perder o caráter pejorativo e agressivo, ainda que em tom humorístico. Concluímos que o discurso em questão associa o sujeito negro ao criminoso, é fundamentado na aparência e no medo, originado de uma ideologia que o percebe como alguém perigoso.
\end{abstract}

Palavras-chave: Discurso; Ideologia; Racismo; Negro.

ABSTRACT: This article has as theme the discussion about a post made on Facebook in 2016, known as "sells a bandit pup". We approached the corpus with a base in pecheutian Speech Analysis, observing the concepts: ideology, interdiscourse, memory and meaning effects. The objective was to draw one analysis about the discourse produced, the circumstances that made possible it's appearance, as well as it's possibilities in the meaning effect. The statements referred of the post were highlighted and related to others collected in media and in other platforms of publication in order to perceive how previous discourses were recovered from other discursive formations and replaced in the post, without, however, lose the pejorative and aggressive character, although in humoristic tone. We concluded that the present discourse associate the black subject to the criminal originated form an ideology that perceive how someone dangerous, reasoned in the appearance and the fear.

Keywords: Discourse; Racism; Ideology; Black people.

\footnotetext{
${ }^{1}$ Graduada em Letras pela UFG/Regional Catalão. Aluna do Programa de Pós-Graduação em Letras da mesma instituição.

${ }^{2}$ Professor Doutor do curso de Graduação e Pós-Graduação em Letras da UFG/Regional Catalão.
} 


\section{Introdução}

Outrora, por inspiração com a teoria da evolução das espécies, concebia-se a humanidade dividida e classificada por raças. Estas determinariam a conduta, o grau de inteligência e as capacidades cognitivas e psicológicas dos indivíduos. Nessa categorização, segundo Fonseca (2012, p. 59), "os africanos ficavam posicionados na escala da evolução, apenas acima dos macacos"; sendo vistos pelos europeus como uma "raça" propensa à violência e à vadiagem.

Em pleno século XXI, o tema "negritude e racismo", longe de se configurar como ultrapassado e/ou uma situação superada pela modernidade e avanços sociais, tem tomado outra roupagem, neste período em que as comunicações evoluíram e se disseminaram. Discursos com conteúdo agressivo, injurioso e preconceituoso circulam na e pela sociedade e chegaram às mídias sociais, locais onde são produzidos, reproduzidos e disseminados sem muito (ou nenhum) controle.

Neste artigo, que ora propomos, analisaremos uma postagem, materializadaem um grupo de compra e vendas no Facebook, causadora de grande repercussão no ano de 2016, pelo fato de se utilizar da imagem de uma criança negra, tatuada e sem camisa, para anunciar a venda de um "filhote de bandido completo". O post, além da imagem, possui várias frases, as quais destacaremos para análise e comparação com outros enunciados. O "investimento" de $\mathrm{R} \$ 1.800,00$, conforme a postagem, seria recuperado em duas semanas, desde que a criança não fosse "levada para a igreja". O jornal $O$ globo, como outros meios de comunicação, noticiou a postagem, informando inclusive que ela foi motivação para que um participante do grupo de vendas procurasse a delegacia, a fim de prestar queixa a respeito do caso, o que foi negado pela delegacia de polícia.

A questão inicial que influenciou esse olhar sobre a referida publicação foi pensar quais circunstâncias históricas permitiram que esse discurso emergisse em pleno século XXI, e quais efeitos de sentido podem ser produzidos a partir dele. Pretendemos buscar os sinais de exterioridade que confluíram na construção de tal postagem, para analisar os discursos que associam o sujeito negro à criminalidade, a fim de refletir sobre as condições de produção que permitem que eles ainda permaneçam em difusão na atualidade, tendo em vista a história dos negros no Brasil.

Usaremos, para abordar essas questões, conceitos da análise do discurso francesa (doravante $\mathrm{AD}$ ), disciplina a qual permite que ultrapassemos a simples leitura superficial e mecânica de textos, ao nos oferecer a possibilidade de observar o discurso para além das 
estruturas textuais (PÊCHEUX, 2011). Além de trazer à tona a história, a memória e o interdiscurso, para perceber a construção dos discursos e seus efeitos de sentido, a AD francesa considera a ideologia como força que atravessa o sujeito e o constitui.

Estamos conscientes de que o discurso presente na postagem provém de uma cadeia de sentidos e enunciados anteriores a ele, dos quais o sujeito enunciador não tem controle. A fim de ampliar a discussão com informações a respeito do racismo no Brasil, lançaremos mão dos estudos de Fonseca (2012) e Almeida (2018), cujas obras se destacam por refletir sobre questões históricas e ideológicas relacionadas à vida dos negros no Brasil.

Este estudo legitima-se por sua contribuição social, tendo em vista a marginalização do sujeito negro na sociedade brasileira, em especial nas situações marcadas por violências, depreciação e preconceito. Presumimos que o discurso materializado na postagem em questão é carregado historicamente de preconceito, o qual se alicerça no discurso domedo, uma construção ideológica que percebe o sujeito negro como perigoso, irremediavelmente violento e propenso ao crime.

O método de análise se baseou em estudos bibliográficos, tomando por base as teorias discursivas pecheutianas, bem como autores brasileiros da área, estabelecendo relação entre elas, além do olhar lançado às pesquisas sobre o racismo no Brasil. O foco deste estudo foi observar a força da ideologia como propulsora do discurso, a influência do interdiscurso e da memória na produção de sentidos. Sabendo que os conceitos se interligam, fizemos adiscussão abarcando os diferentes tópicos da $\mathrm{AD}$, a partir dos argumentos sobre a língua e linguagem, e observando os principais elementos e as possíveis direções que pode tomar o discurso.

O caminho percorrido consistiu em tomar o post, desmembrar os enunciados, traçar paralelo com outros discursos, notando os interdiscursos presentes, como a memória e a ideologia influenciam nesses discursos, bem como quais os efeitos de sentido podem ser produzidos a partir deles. Cada enunciado destacado foi associado a outros de formações discursivas que se relacionam a diferentes formas de interação, em especial, as de âmbito comercial, a fim de comparar e encontrar os traços de memória ativados, os discursos recuperados e as novas possibilidades de construção de sentido. Por outro lado, relacionamos o discurso selecionado com outros produzidos na mídia e na história sobre a temática do racismo e da escravidão.

Ao utilizar a $\mathrm{AD}$ como viés teórico para observar nosso objeto de análise, descrevemos o contexto social e condições de produção que envolvem a emergência do discurso materializado na postagem; apontamos o modo como se constituiu historicamente o 
discurso que faz a associação entre sujeito negro a criminalidade/violência,verificando como essa relação possibilita a produção de efeitos de sentido e quais efeitos de sentido são produzidos, tendo em vista a história do negro no Brasil. Destaque maior foi dado aos enunciados textuais, tendo nos detido na imagem apenas para tratar de questões relativas à construção de sentido, deixando análises mais profundas, no âmbito imagético, para produções futuras.

\section{Análise discursiva da postagem}

O discurso, como já explicitado, é anterior ao sujeito, e permanecerá depois dele. Assim, quando certos enunciados são proferidos, como: "vende-se um filhote de bandido", ele virá carregado de sentidos que têm um lastro histórico, por recuperar outros discursos anteriores a ele, e acionar elementos de uma memória discursiva que pode até mesmo ter sido esquecida. Discurso algum, observando por tal viés, alcança transparência ou neutralidade, já que, para a $\mathrm{AD}$, não existe relação entre sujeito, sua existência e o mundo sem ideologia. Não trabalharemos, portanto, com a ideia de construção discursiva transparente, simples transmissora de informações e acontecimentos, ou com a ideia de postagens que sejam apenas transmissoras de humor ingênuo, mas, com a premissa de que um sujeito discursivo, atravessado por múltiplos discursos e múltiplas vozes que o constituem, um sujeito ocupante de um dado lugar, de uma dada posição, revelada em seu discurso e responsável por ele.

Não nos estenderemos em maiores discussões a respeito de gênero, Facebook ou post, basta, para a análise em questão, que, em Bakhtin (1997, p. 280), compreendemos que "cada esfera de utilização da língua elabora seus tipos relativamente estáveis de enunciados, sendo isso que denominamos gêneros do discurso". Consideramos o espaço virtual de usuários da internet como uma esfera na qual o Facebook funciona como um gênero digital (MARCUSCHI, 2005), uma plataforma interativa de comunicação interpessoal, mediada por meio eletrônico. Essa comunicação se dá por meio de postagens - comumente chamadas posts -; ou seja, o post, conforme trataremos aqui, é um dos modos pelos quais o usuário compartilha mensagens e informações nesse ambiente virtual, e pode ser composto por imagem, textos e sons em diversas configurações.

Abaixo, apresentaremos a postagem, e, após isso, com os enunciados desmembrados e dispostos conforme a formação discursiva identificada, e com a qual traçaremos paralelos, 
observaremos os pontos de conexão e interdiscursividade, os movimentos linguísticos entrelaçados por essa memória, e os efeitos de sentido produzidos.

\subsection{O post "vende-se um filhote de bandido" - discurso e interdiscurso na construção do enunciado}

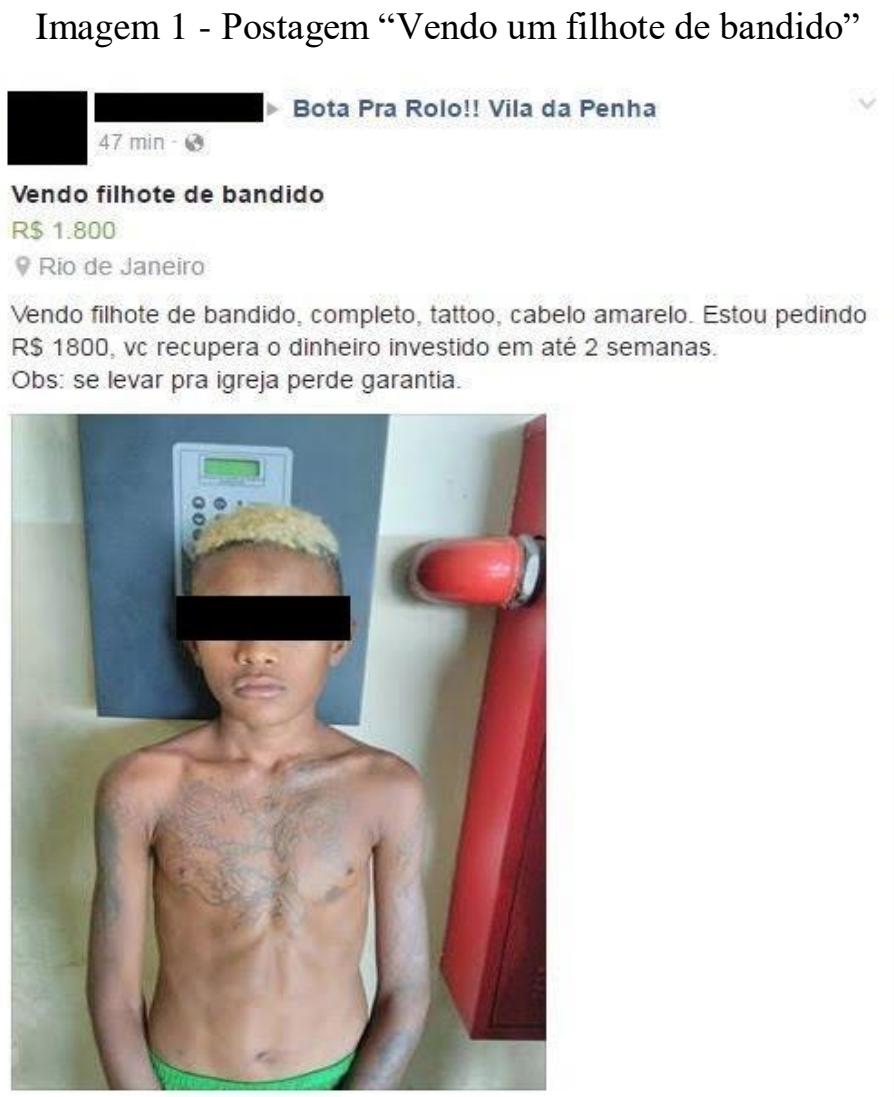

Fonte: $O$ Globo. ${ }^{3}$

O post selecionado é composto pela imagem de um menino sem camisa, com tatuagens pelo corpo, cabelo tingido, com a sobrancelha raspada, complementada com a seguinte construção textual:

Vendo filhote de bandido. Ano 2006. Completo. Tattoo. Cabelo amarelo. Sobrancelha riscada. Pircing. Estou pedindo1,800 \$. Recupere o dinheiro em até duas semanas.

Obs. Se levar pra igreja perde garantia kkkkk.

Interessados chamar in box.

Algo que sempre é declarado quando discursos preconceituosos são questionados e criticados, é que não houve intencionalidade de produzir ou reproduzir discurso racial

3 Disponível em: <https://blogs.oglobo.globo.com/ancelmo/post/publicitario-publica-em-rede-social-foto-demenor-e-diz-vendo-filhote-de-bandido.html>. Acesso em: 10 ago. 2019. 
$\left(\right.$ NASCIMENTO; RIBEIRO, 2018) ${ }^{4}$. Para a AD, contudo, a intenção de dizer ou não algo não é considerada, pois o sujeito que enuncia o discurso "não é livre, e não está na origem do discurso" (POSSENTI, 2004, p. 385), e rompe-se, portanto, com essa concepção de que o sentido é planejado pelo autor, para ir ao encontro da exterioridade que constitui o enunciado. Neste trabalho, então, pretendemos buscar os sinais dessa exterioridade que confluíram na construção de tal postagem.

Para a análise, procederemos da seguinte forma: iremos fragmentar o discurso em trechos, a fim de construir a análise, ao traçar um paralelo com as outras postagens e outros discursos anteriores a eles. Dividiremos, a fim de obter mais clareza nas análises, os enunciados da seguinte forma:

Enunciado 1 - vende-se filhote de bandido. Ano 2006. Completo. Tattoo. Cabelo amarelo. Sobrancelha riscada. Pircing.

Enunciado 2 - Estou pedindo 1,800 \$. Recupere seu dinheiro em até duas semanas.

Enunciado 3 - Obs. Se levar para a igreja perde a garantia.

Observaremos como cada enunciado constrói o efeito discursivo, ao verificar quais discursos podem ser recuperados ou acionados a partir deles. Assim, a linguagem está irremediavelmente conectada àquilo que circula por seu exterior e que nela se materializa. Sob a perspectiva da $\mathrm{AD}$, que tem no texto, ou seja, na materialidade linguística, sua unidade basilar de estudo, Orlandi (2015, p.8) define discurso como "o ritual da palavra", nele, os sentidos são construídos, modificados, cristalizados. É nele que estão alocados os conflitos entre aqueles que se comunicam. Isso resulta do fato de que cada participante do discurso o interpreta a seu modo, de acordo com sua historicidade e formação ideológica na qual está inserido. A Análise do Discurso, para essa autora, toma o discurso como aquilo que media a relação entre o homem e sua realidade.

Orlandi (2015) ainda diz que a AD toma o discurso como aquilo que intermedia a relação entre o homem e a realidade. O texto não tem respostas em si mesmo, pois, ao analisar o discurso, analisamos não apenas asproposições gramaticais, mas todas as construções

\footnotetext{
${ }^{4}$ Para observar como os discursos relativos ao sujeito negro são concebidos na e pela mídia, ver o texto: Uma análise discursiva dos memes "Nego isso, Nego aquilo" (NASCIMENTO, 2018). Percebe-se, nesse estudo, a existência de discurso racista nos memes citados, evidenciado pela exclusividade de sujeitos negros nas imagens. As postagens, porém, são comumente concebidas como humor inocente sem teor racista. Percebemos que tais justificativas ocorreram justamente pelo fato de o humor camuflar o discurso preconceituoso, angariando, em muitos casos, defensores da ideia de que tais postagens são apenas brincadeiras.
} 
históricas e de memória, já que a língua é, para a $\mathrm{AD}$, uma prática social e política, pelo fato de materializar ideologias. Esse sentido anterior é a memória discursiva, que é social e coletiva, e é "trabalhada pela noção de Interdiscurso: 'algo fala antes, em outro lugar, independentemente" (ORLANDI, 2006, p. 21), é o movimento do discurso, pode-se dizer que o sujeito mobiliza as palavras de outros para produzir o seu próprio discurso.

O entrecruzamento de outros e diferentes enunciados é observável em posts, memes e variados tipos de construções discursivas, como na que ora selecionamos. A todo o momento, elas retomam um discurso anterior, para construir seus enunciados. Essa característica é constituinte da materialidade discursiva; contudo, é mais que um recurso de escrita. $\mathrm{O}$ atravessamento da voz do outro é constitutivo do discurso, que trará em si outros discursos enunciados antes dele, e, com eles, os sentidos produzidos, mesmo aqueles esquecidos e substituídos; dessa maneira, sempre apontará a algum “já dito” (ORLANDI, 2015, p. 34). Abaixo, observaremos alguns discursos recuperados pela postagem.

Observemos o trecho do Enunciado 1:

Vendo filhote de bandido. Ano 2006. Completo. Tattoo. Cabelo amarelo. Sobrancelha riscada.

Quais outros discursos semelhantes a este podem ser encontrados, onde se manifestam e qual situação para seu aparecimento? Esse tipo de construção pode ser encontrado com facilidade em classificados e outros anúncios de venda, especialmente, quando o objeto é um carro. Vejamos um anúncio retirado de um site que comercializa automóveis:

Exemplo 1 - Venda de carros - Fiat - Siena 2002. completo por um preço de R $\$ 18.500,00$. Opções: alarme. Ar quente. Desembaçador traseiro. Manual do proprietário. Rodas de liga leve. Vidro elétrico. Cópia da chave. Direção hidráulica. Rádio e CD player. Travas elétricas. ${ }^{5}$

Notemos os termos comuns a estes dois discursos. Ambos materializam discurso comercial de anúncio de mercadoria, dando ênfase aos atributos daquilo que se intenciona vender. Na venda do carro, destacamos os termos: vende-se - completo - 2002. Além disso, outro fator marcante no anúncio são as descrições do automóvel. Mesmo declarando que se tratava de um veículo completo, a propaganda ainda reitera quais são os itens que, ao serem elencados, garantem ao bem o predicado de completo. Do mesmo modo, na postagem "vendese um filhote de bandido", os termos: "vende-se", "ano 2006", e "completo", conduzem a

\footnotetext{
${ }_{5}^{5}$ Disponível em: <http://carros.viaki.com/mercado/carros/go/goiania/fiat/siena/8206-p/siena-2002-completo〉. Acesso em: 10 out. 2019.
} 
Raquel Costa Guimarães Nascimento; Antônio Fernandes Júnior. Discurso, história e memória a partir do post "vende-se um filhote de bandido".

certo efeito de sentido, sobretudo, ao recuperar termos usados em enunciados de anúncios de venda de carro, por conter termos próprios desse tipo específico de gênero textual. Os anúncios materializados em classificados de jornais ou sites de venda, comumente, veiculam a venda de automóvel, utilizando-se dessas estratégias descritivas.

Ora, ao anunciar a venda de um filhote de bandido fazendo uso de tais termos, a postagem pode criar um efeito de sentido que associa o menino a um bem de consumo, uma coisa, um objeto, tal qual um automóvel. Para efeito de comparação, buscamos discursos em que pessoas foram anunciadas dessa forma. Freyre (2012, p. 50) informa que, em jornais antigos, era comum que os anúncios de venda de escravos, bem como a descrição de escravos fugidos chegassem a tomar dois terços dos jornais e diários do século XIX. Selecionamos os seguintes anúncios, dentre vários coletados pelo autor, dando enfoque aos que contêm descrições físicas das pessoas postas a comércio:

Exemplo 2 - Vende-se [...] Huma escrava crioula, idade 16 anos, engoma lizo, lava roupa de sabão, cozinha o diário de humacaza, faz pandeló, coze xão, e sabe tratar de meninos, sem vício, muito sadia, bonita figura (FREYRE, 2012, p. 100).

Exemplo 3 - "Vende-se um escravo velho próprio para botar sentido a sítio, pastorar vacas, vender frutas e leite (FREYRE, 2012, p. 97).

Exemplo 4 - Vende-se um escravo pardo, de 36 anos de idade, boa figura e muito desembaraçado e inteligente para todo o serviço (FREYRE, 2012, p. 98).

Exemplo 5 - Vende-se na rua do Sebo [...], uma negra crioula, idade 25 anos, parida há 10 meses, com leite, sem cria, cozinha, faz doce, engoma, cose: ao comprador se dirá o motivo da venda (FREYRE, 2012, p. 100).

Exemplo 6 - Vende-se uma escrava boa cozinheira, engomma bem e ensaboa, com uma cria de 3 anos, peça muito linda, propria de se fazer um mimo della; e tambem se vende só a escrava, no caso que o comprador não queira com a cria (FREYRE, 2012, p. 98).

Notamos que o anúncio posto em redes sociais, em 2016, recupera, via memória discursiva, o discurso de venda de escravos do século XIX. O termo "vende-se", seguido das descrições físicas e de atributos e qualificações para o trabalho, era comum naquele tipo de construção enunciativa. Aqui percebemos o papel da memória como fonte de interdiscurso para o alçamento de retomada daqueles dizeres próprios do período escravocrata. $\mathrm{O}$ interdiscurso

[...] é o lugar no qual se constituem, para um sujeito falante, produzindo uma sequência discursiva dominada por uma FD determinada, os objetos de que esse sujeito se apropria para deles fazer objetos de seu discurso, assim como as 
articulações entre esses objetos, pelos quais o sujeito enunciador vai dar uma coerência à sua declaração (COURTINE, 2009, p. 74).

Assim, cada palavra que é dita ou escrita, seja em um áudio, vídeo, comentário ou postagem, não é meramente um instrumento transparente na comunicação, mas um elo em uma teia de significados, que serão retomados e reconstruídos. Quem enuncia (ou em nome de quem se enuncia), sobre o que se fala/escreve, e para quem se fala/escreve, determinará os efeitos de sentido daquilo que é dito/escrito, que não será óbvio ou gratuito, mas um recorte de um processo discursivo maior, mais amplo e móvel (ORLANDI, 2015).

Assim, quando certos enunciados são proferidos, eles vêm carregados de sentidos que têm um lastro histórico. Esse sentido anterior é a memória discursiva, lugar do "já dito" (ORLANDI, 2015, p. 34), que é social, coletiva e trabalhada pelo interdiscurso, como algo que fala antes, "em outro lugar, independentemente" (ORLANDI, 2006, p. 21). É no movimento do discurso que o sujeito mobiliza as palavras de outros para produzir o seu próprio discurso.

\subsection{Recupere seu dinheiro em até...: as formações discursivas sobre investimento financeiro}

Passemos, agora, à reflexão sobre o enunciado: recupere seu dinheiro em até... Onde ele circula? Esse enunciado pode ser, comumente, visto em anúncios de investimentos financeiros, como neste abaixo:

ENUNCIADO 2 - Tôpedindo1,800 \$. Recupere o dinheiro em até duas semanas.

EXEMPLO 7 - O investimento em uma unidade da rede parte de 11,99 mil reais e o prazo para retorno de investimento é de três a 12 meses.

As construções enunciativas do post remetem a formações discursivas (FD) de investimentos financeiros. As formações discursivas, segundo Pêcheux (2011), estão dentro de formações ideológicas, e definem o que é passível de ser dito, bem como suas possibilidades combinatórias. Courtine (2009) acrescenta que "as FD são componentes interligados das FI", e, além disso, "é no interior delas que se realiza o 'assujeitamento' do sujeito (ideológico) do discurso". 
Raquel Costa Guimarães Nascimento; Antônio Fernandes Júnior. Discurso, história e memória a partir do post "vende-se um filhote de bandido".

Notamos certa equivalência ao observar as formações discursivas encontradas em sites ou em anúncios de venda de bens como franquias ou energia solar. Vejamos a seguinte análise de custo / retorno de investimento de energia solar.

EXEMPLO 8 - Se fizermos uma estimativa nacional, o tempo de retorno do investimento pode ser menor do que 5 anos [...]. Portanto, como estes sistemas possuem mais de 25 anos de vida útil, [...] serão mais de 17 anos de energia gratuita!

Na postagem da venda do filhote de bandido, percebe-se o atravessamento desse tipo de discurso proposto no anúncio ou propaganda, ou seja, um item é avaliado conforme sua capacidade de dar certo retorno financeiro. O que coloca, mais uma vez, o item à venda em relação parafrástica, ou de sinonímia, com enunciados relativos a negócios envolvendo bens de consumo, recuperando esses outros discursos e essas formações discursivas. O fato de anunciar o retorno garante a "qualidade do investimento".

No exemplo 7, trata-se de uma franquia, ou seja, a abertura de um negócio, o dinheiro seria recuperado na medida em queas vendas fossem feitas; já, no exemplo 8, em que se investe em energia solar, trata-se de um equipamento que, em longo prazo, se reverterá em economia de dinheiro e retorno do investimento pela medição do custo benefício. Nos dois casos, essa avaliação de custo demonstra que se trata de uma negociação de valor garantido. Como "o filhote de bandido" se recuperaria o dinheiro/investimento? Partindo dessa questão, analisaremos a sequência discursiva seguinte.

\subsection{Se levar para a igreja perde a garantia - sentidos e memória}

Pechêux (2011) considera a linguagem ativa nas relações de classes sociais, pois ela é simbólica, mediadora, e, ainda, segundo Orlandi (2012, p. 152), uma prática, na perspectiva em que atua como mediadora entre sujeito e realidade. $\mathrm{O}$ enunciado 3 demarca esse lugar simbólico, ao demonstrar que o ambiente de convívio do sujeito pode ter impacto sobre seu comportamento, e ainda é possível perceber a ironia marcada pelo “ $k k k$ ”, expressão usada nos gêneros digitais para indicar riso.

\section{Enunciado 3 - Se levar pra igreja perde a garantia kkkk}

Acionaremos os conceitos de efeitos de sentido, a fim de perceber como esse enunciado confere sentido ao post. Cada discurso trará imbuído em si os outros discursos 
enunciados antes dele, trarão também outros sentidos produzidos, mesmo que esses sentidos tenham sido esquecidos e substituídos, pois um discurso sempre fará alusão a outros. Texto algum pode ser tomado como algo fechado e que possui respostas em si mesmo. Do mesmo modo em que uma piada não deve ser tomada inocentemente, como algo apenas ligado ao entretenimento, pois ela aciona discursos anteriores a ela. A partir desse ponto, passa-se a produzir, dentro de determinado contexto, o efeito de sentido, que não é obvio, não é dado, mas varia de acordo com leitor, autor, texto e condições de produção; o efeito de sentido sofrerá variação de acordo com quem fala, sobre o que fala e para quem fala. De acordo com Orlandi (2015, p. 37), o sentido nada mais é que um recorte de um processo discursivo maior, mais amplo e móvel. Tais efeitos serão provenientes da Ideologia, que é responsável por “interpelar o indivíduo em sujeito" (ORLANDI, 2006, p. 19), e, a partir desse gesto, produzir interpretações.

Então, em relação ao objeto tratado, será possível filiar-se a certos sentidos, de modo que o post "Vende-se um filhote de bandido" não poderá ser tomado independentemente de discursos anteriores, mesmo que esquecidos, bem como da ideologia à qual ele se vincula, nem como apenas uma simples piada. O enunciado “garantia” também é usado, comumente, ao se tratar de algum bem de consumo, alguma mercadoria, objeto. Seja um automóvel, eletrodoméstico, aparelho celular ou de informática em geral. Em muitos casos, as empresas vendem uma garantia adicional, a fim de aumentar o período de cobertura da garantia (e os ganhos obtidos com essa venda), que é algo que irá proteger o bem de prováveis perdas ou prejuízos. Essa garantia se perde em casos em que acontece o uso inadequado do item.

Na postagem veiculada, no grupo de vendas da rede social, o que causaria a perda dessa garantia seria o fato de permitir a inserção do "filhote de bandido" em uma igreja. Como essa situação, poderia interferir na "qualidade do produto", causando a perda da garantia? No imaginário popular, têm-se uma ideia de que, ao frequentar uma igreja, uma pessoa poderá "mudar de vida, de comportamento", assim, se o "filhote de bandido" passar a conviver nesse ambiente, ele poderá deixar de cometer delitos, o que acarretará em não arrecadar dinheiro para seu proprietário, fazendo com que sua utilidade se perca, assim como o retorno do investimento.

Existe uma compreensão de que a igreja recebe os desajustados e opera sobre eles uma mudança de comportamento, através do controle exercido sobre eles. A igreja, como um aparelho ideológico do estado (ALTHUSSER, 1980, p. 111), age interpelando o sujeito através da ideologia, controlando suas ações e o readequando ao padrão de normalidade de comportamento esperado, de quem se submete ao Sujeito superior (Deus) e passa a se 
comportar conforme é esperado de alguém dentro dessa instituição. Desse modo, o sujeito passa a se adequar a um comportamento que é esperado dele para a vida em sociedade, sendo controlado e domesticado. Nesse caso, o menino, que deixaria de cometer seus delitos, acabaria comprometendo o investimento do comprador.

É possível observar um discurso em que a ação ilegal da criança não parece tornar ilegal ou causar qualquer constrangimento a quem vende ou a quem compra a criança com propósito de aliciá-la para atitudes ilícitas. É visto como problema ou dano tão somente o fato de o menor ter seu comportamento modificado pela igreja. Cabe, aqui, traçar outro paralelo como anúncios de século passado, nos quais os escravos eram alugados para prestar algum serviço, muitas vezes, com altos riscos, em que, geralmente, homens livres não eram estimulados a atuar. O lucro do trabalho desse escravo, nessa função, era destinado ao seu dono, como no anúncio a seguir:

Exemplo 9 - Alugam-se pretas que sabem vender na rua (FREYRE, 2012, p. 76).

Exemplo 10 - A pessoa que tiver escravos e quiser alugar para trabalhar na estrada de ferro, pagando-se mil réiz por dia (FREYRE, 2012, p. 76).

A postagem inicial deste estudo remete, mais uma vez, a discursos de períodos de escravidão, em que o trabalho do outro, seja legalizado, escravizado, ou mesmo sugerido na forma de brincadeira, conduz ao lucro não daquele que trabalhou, mas do seu dono, aquele que investiu em sua posse.

\subsection{Ideologia, sujeito e imaginário: o que permitiu que esse discurso associasse o sujeito negro ao bandido?}

Além de trazer à tona a história, a memória e o interdiscurso, para perceber a construção do discurso e seus efeitos de sentido, a AD francesa considera a ideologia como força que atravessa o sujeito e o constitui. Desse modo, ao utilizá-la como viés teórico para contemplar nosso objeto de análise, estamos conscientes de que o discurso presente na postagem provém de uma cadeia de sentidos e enunciados anteriores a ele, dos quais o sujeito enunciador não tem controle. Como analistas, então, além do material gráfico selecionado(trechos de construções linguísticas), analisaremos as construções históricas e de memória discursiva ligadas a elas, já que a língua é, para a $\mathrm{AD}$, uma prática social, política, 
Raquel Costa Guimarães Nascimento; Antônio Fernandes Júnior. Discurso, história e memória a partir do post "vende-se um filhote de bandido".

materializada pela ideologia. Importará, nesse sentido, ao tratarmos dos enunciados, estarmos atentos às construções ideológicas que os cercam, constituem e atravessam.

Para Pêcheux (2011) o sentido não será encontrado no indivíduo, por meio de conjuntura subjetivista, mas nas relações sociais provindas de relações de classe. O indivíduo, pois, intimado em sujeito pela ideologia, não é central para a formação de sentido, tampouco senhor de sua fala, já que ele será guiado pelo contexto e pela ideologia.A ideologia, que está na base de qualquer construção comunicacional, é responsável por "interpelar o indivíduo em sujeito" (ORLANDI, 2015, p. 44), e é, além disso, condição indispensável para a produção de sentidos de qualquer enunciado, seja ele oral ou escrito, como uma conversa, um discurso político, uma postagem ou uma reportagem. É a partir dela, a ideologia, que se formam os discursos e os sujeitos, pois, para os autores nos quais nos apoiamos, não é o sujeito que fala, pelo contrário, ele é falado pela ideologia, condicionado por aquilo que é exterior à linguagem e a ele próprio. Este sujeito, qualquer que seja, não cria os efeitos de sentido daquilo que enuncia; pelo contrário, ele próprio é um efeito do discurso (ORLANDI, 2015).

O sujeito não enuncia sozinho, como vimos, esses discursos, com conteúdo discriminatório, e que naturalizam o negro em lugares sociais inferiores, circulam por outros gêneros e outros ambientes de diversas formas. Almeida (2018), ao discutir a naturalização do racismo, argumenta que a mídia televisiva reproduz estereótipos das pessoas negras no país, demarcando, por décadas, o lugar de submissão da mulher negra, e conferindo ao homem negro o papel de bandido e marginal. Segundo ele, essas performances não refletem a realidade, mas são "uma representação do imaginário social acerca das pessoas negras. A ideologia, portanto, não é uma representação da realidade material, das relações concretas, mas a representação da relação que temos com essas relações concretas" (ALMEIDA, 2018, p. 51). O autor reitera ainda que:

O imaginário em torno do negro criminoso representado nas novelas e nos meios de comunicação não poderiam se sustentar sem sistema de justiça seletivo, sem a criminalização da pobreza, e sem a guerra às drogas. Ademais, a própria indiferença teórica sobre a desigualdade racial nos campos político e econômico é fundamental para constituir um imaginário racista, pois assim, sem críticas, ou questionamentos, a discriminação racial ocorrida nas relações concretas aparecerá à consciência como algo absolutamente normal (ALMEIDA, 2018, p. 52, grifos do autor).

Assim, ações efetivas "moldam" o inconsciente, pautadas nos padrões de reconhecimento e afetividade com o outro. Segundo o especialista, a escola ainda contribui para esse padrão, por não apresentar contribuições de negros em literatura, ciências ou outros 
avanços, exibindo o povo negro tão somente como aquele beneficiado com a bondade da classe branca. Mielke (2017, p. 8) apresenta uma pesquisa sobre a presença (ou não) do sujeito negro na produção televisiva brasileira. Ela afirma que, além do silenciamento causado pela não representatividade desses sujeitos na TV, os papéis nos quais esses personagens são apresentados reforçam estereótipos, negando a valorização da identidade negra, que é relegada a "ocupar um lugar" periférico e já determinado na sociedade.

Vemos, partindo dessa premissa, que a relação discursiva se dá não apenas a partir dos sujeitos do discurso, mas também a partir daquilo sobre o que se enuncia. Para discutir tais discursos, além dos argumentos já mencionados, tomemos o que disse Fiorin (2003, p. 55) a respeito da linguagem e sua condição de difundir valores:

A linguagem tem influência também sobre os comportamentos, do homem. O discurso transmitido contém em si, como parte da visão do mundo que veicula, um sistema de valores, isto é, estereótipos dos comportamentos humanos que são valorizados positiva ou negativamente. Ela veicula os tabus comportamentais. A sociedade transmite aos indivíduos - com a linguagem e graças a ela - certos estereótipos que determinam comportamentos.

Pesquisa do Instituto Datafolha ${ }^{6}$ de 1995 apontou, no Brasil, a existência do que o editorial chamou de racismo cordial, baseada em uma extensa investigação pautada em dados quantitativos e em um conjunto de perguntas indiretas feitas à população. "Negro quando não faz besteira na entrada, faz na saída" e "Negro bom é negro de alma branca" foram algumas das frases com as quais a grande parte dos entrevistados concordou, demonstrando, assim, a preponderância dessa pré-concepção com relação aos sujeitos negros. Segundo a pesquisa, $87 \%$ dos não negros manifestavam algum tipo de preconceito contra negros.

Afirma-se, ainda, no imaginário, a ideia de necessidade dehigiene social, pois, se o sujeito não possui condições de se integrar à sociedade, cabe-lhe o isolamento, ou mesmo o aviltamento na forma de piadas depreciativas. Situações em que sujeitos negros passam por constrangimentos ao serem relacionados a escravos não são incomuns nas redes sociais. Como exemplo, podemos citar o caso ocorrido em março de 2018, em que uma postagem no Facebook declarava: "um escravo achado no fumódromo" causar revolta. Tratava-se da foto

\footnotetext{
${ }^{6}$ Disponível em:

<http://almanaque.folha.uol.com.br/racismocordial.htmhttps://acervo.folha.com.br/leitor.do?numero=12830\&an chor $=505634 \&$ origem $=$ busca\&pd=b7e571b580dbe7a9bf8e6144cfec3d1c >. Acesso em: 12 out. 2019.
} 
de um estudante da Fundação Getúlio Vargas, tirada por outro aluno da instituição sem seu conhecimento.

Ao analisar tais construções discursivas, e sabendo que o sujeito não é senhor de sua fala, mas é levado inconscientemente a produzir um discurso por forças ideológicas e históricas exteriores e anteriores a ele, qual o papel do sujeito emissor do discurso? Ele é “desculpável” por aquilo que diz, já que não é ele quem controla seus dizeres? Qual o papel do sujeito de quem se fala - no caso, o menino fotografado na publicação, e do o sujeito para quem se fala, aquele que recepciona a postagem? A fim de esclarecer tal ponto, podemos citar Possenti, que diz:

A $\mathrm{AD}$ rompe com a concepção de sentido como projeto do autor, com a de um sentido originário a ser descoberto; como a expressão das ideias de um autor sobre as coisas; com a concepção de texto transparente, sem intertexto, sem subtexto; com a noção de contexto cultural dado como se fosse uniforme (2004, p. 360).

O sujeito, então, não é a fonte do discurso, muito menos dos sentidos produzidos, pois, como dito, a análise do discurso não estuda o indivíduo ou sujeito empírico, mas a posição sujeito como uma função. Nesse caso, o sujeito ocupa a função discursiva de autor e, como tal, "o sujeito ao mesmo tempo em que reconhece uma exterioridade à qual ele deve se referir, ele também se remete a interioridade, construindo sua identidade como autor" (ORLANDI, 2015, p. 74). A autora ainda argumenta que, além danecessidade de estar inserido na cultura, assumindo esse papel social, esse sujeito autor encontra seu correspondente, no sujeito leitor, que será também configurado identitariamente pelo seu lugar social, e o torna responsável por sua leitura, reprodução e compartilhamento, no caso de postagens de redes sociais.

As relações imaginárias, como vimos, interferem na construção do discurso e formação de sentidos, elas formam um sistema de representação coletiva, social e histórica, capaz de ser resgatável. Nelas, segundo Orlandi (2015), podemos explicitar dois pontos fundantes: o primeiro diz respeito à relação de forças, que atuam como garantidoras do nível de autoridade daquele que enuncia, autoridade essa conferida pelo lugar hierárquico de cada um na sociedade. Afirmar isso significa que o sujeito enuncia o que enuncia porque seu lugar social lhe permite.

O segundo refere-seàs imagens que cada participante do discurso faz de si e do outro, e que são determinantes para a troca de palavras dentro do discurso. A percepção que os sujeitos envolvidos no jogo discursivo têm sobre si e sobre os outros intervêm diretamente na escolha de palavras do discurso. É o que podemos observar no discurso produzido na postagem selecionada. Orlandi (2015) explica essas interferências do seguinte modo: 
[...] temos assim a imagem da posição sujeito locutor (quem sou eu para the falar assim?), mas também da posição do sujeito interlocutor (quem é ele para me falar assim ou para que eu lhe fale assim?), e também a do objeto do discurso (do que estou lhe falando, do que ele me fala?). É, pois, todo um jogo imaginário que preside a troca de palavras (ORLANDI, 2015, p. 38).

Nota-se, com isso, o caráter profundamente simbólico da linguagem e das relações como traço fundamental nos estudos do discurso. Essa simbologia está presente nas descrições feita na postagem que nos propomos a estudar. Completa a construção discursiva os esquecimentos. Esquece-se que o sujeito não é fonte do discurso, mas ele o retira de uma historicidade, e esquece-se que o que foi dito poderia ser dito de outra forma. Pode-se falar do outro com outras palavras, e, desse modo, produzir outros sentidos.

\subsection{Por que o discurso humorístico "filhote de bandido" e não outro em seu lugar?}

O lugar marcado pela ideologia confere, assim, um destino não apenas ao adulto negro, mas também à criança. Estereótipo marcado pela força do dizer popular "filho de peixe peixinho é...”. Define-se, assim, um lugar marcado socialmente. O discurso é um dos "aspectos materiais da ideologia" (COURTINE, 2009, p.7). É uma das diversas formas de manifestação daquilo que consideramos uma força social, que é histórica e coletiva, e atravessa os sujeitos.

$\mathrm{Na}$ ocasião em que a publicação em pauta ocorreu, várias postagens foram feitas no Facebook, anunciando filhotes de algum animal exótico ou selvagem. Diferentemente das outras postagens, esse anúncio oferece uma pessoa. Ela toca os bordos da escravidão ao anunciar a venda de um ser humano. O sujeito negro é marcado nesse post, ademais, como animal, fazendo parte de um conjunto de postagens em que um animal é fantasiado como outro, a fim de atingir certa comicidade e levar ao riso. Passemos a observar qual o papel do humor na referida construção discursiva. Qual o efeito de sentido em se inserir uma imagem de um menino em um conjunto de imagens de animais como o que segue abaixo? 
Raquel Costa Guimarães Nascimento; Antônio Fernandes Júnior. Discurso, história e memória a partir do post "vende-se um filhote de bandido".

Imagem 2 - Postagens do conjunto de "vende-se" animais exóticos

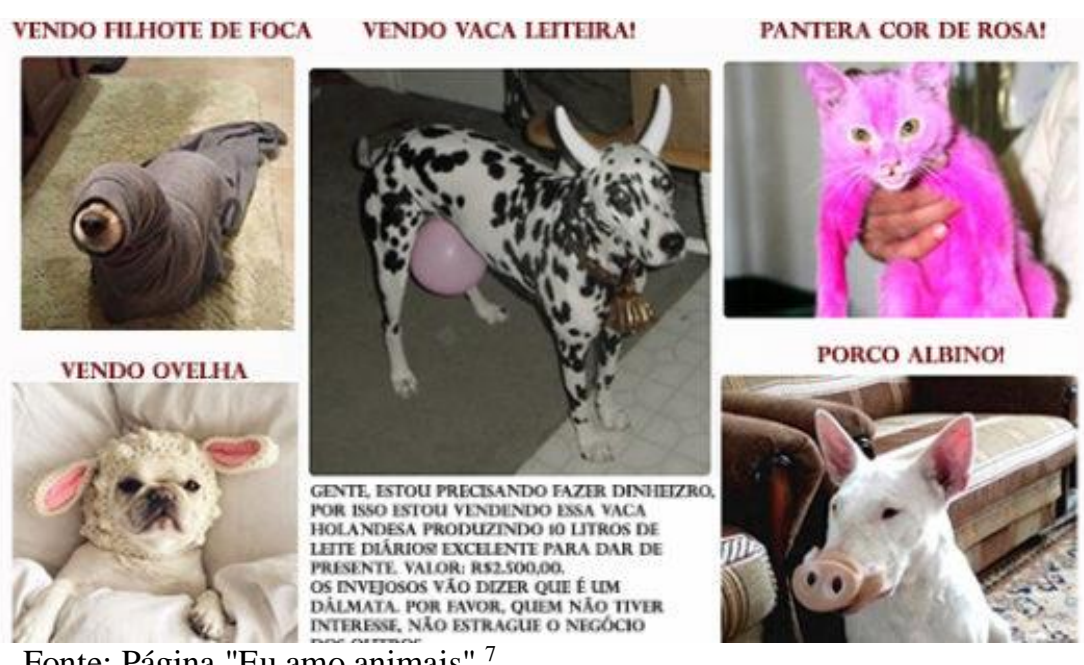

Fonte: Página "Eu amo animais".?

A memória discursiva novamente é acionada nesse enunciado, trazendo à tona discursos comuns em jornais do século XIX. Segundo Freyre (2011, p.101), em suas pesquisas sobre os anúncios de venda,

Os escravos, igualmente, já vimos que vêm muitas vezes anunciados, para venda, nos jornais brasileiros do século passado, entre animais e no meio de diversos objetos; entre cavalos, cabras, foles para oficinas ou ouvires, um Don Quixote em espanhol, uma espingarda de passarinhar de meia coronha, um fardamento para pajem em bom uso, as obras de Voltaire a $3 \$$. Cabra, quando é o animal que se tem para vender, sempre se diz, nos anúncios, cabra-bicho. Que é para não se confundir com a cabra-mulher. Do contrário, o leitor ficaria na dúvida sobre as "cabras de bom leite" que aparecem frequentemente nos anúncios. Os anúncios de cabras, isto é, negras, mulheres de cor, amas de leite, são numerosos; às vezes negras "com abundante leite aprovado pelos Professores".

Fonseca (2012), em seus estudos, trata da subjetivação do sujeito negro, da ideologia que posiciona esse sujeito como objeto risível e de como as palavras, os termos e associações simbólicas podem corroborar para a desqualificação de um sujeito ou de uma comunidade. Fonseca (2012) faz um traçado histórico a respeito da piada sobre negros no Brasil, desconstruindo a ideia de brincadeira inocente, e imputando graves consequências em tais chistes. Para o autor, o riso, em atitude de superioridade, desumaniza o outro, mascara e suaviza a ideologia preconceituosa, segundo a qual o negro adquiriu o status de cidadão de segunda categoria, causada por sua cor, desde o período do império. Essa relação com a cor define relações que têm designado de maneira pejorativa a população negra.

\footnotetext{
${ }^{7}$ Disponível em: 〈https://euamoosanimais.com.br/classificados-animal-negocios-humor-3/>. Acesso em: 10 out. 2018.
} 
Raquel Costa Guimarães Nascimento; Antônio Fernandes Júnior. Discurso, história e memória a partir do post "vende-se um filhote de bandido".

No imaginário e na ideologia dos aparelhos coercitivos e repressivos da sociedade, cimentou-se a ideia de que o negro é vagabundo, vadio, ladrão. Portanto, até que se prove o contrário, ele é perigoso. A construção desse imaginário é parte da "síndrome do medo" que se abateu sobre a elite brasileira, o período escravista, em virtude das diversas revoltas e insurreições de africanos e seus descendentes (FONSECA, 2012, p. 94).

Mesmo as produções fílmicas internacionais são influenciadas por esses estereótipos. Roberts (2006) analisa a presença desse medo do negro na criação de personagens da ficção científica, como o alienígena de um dos filmes da série Alien (1979), que representa, segundo o autor, o possível estrangeiro, negro, habitante de áreas urbanas violentas, que ataca suas vítimas de maneira bárbara e violenta. Roberts (2006) afirma que as características físicas do monstro são claramente uma representação da negritude. Mesmo que o negro não seja um estrangeiro, ainda assim, sua presença pode ser percebida como diferente, deslocada e indesejada, caso não se adapte aos padrões impostos pela ideologia vigente.

A publicação no Facebook ou as reportagens publicadas em jornais sobre o caso usam a imagem de um menino com características marcantes. Contudo, em momento algum, existe a informação de quem ela seja, qual a sua situação social e familiar, ou em qual circunstância a foto usada foi tirada. Isso não impediu que a postagem sugerisse que se tratasse de um "minibandido" baseado apenas na imagem. Os comentários postados no site do jornal $O$ Globo, abaixo da notícia, igualmente, sinalizam que as marcas estereotipadas definidas pela ideologia, conforme dito acima, influenciam o discurso dos sujeitos com julgamento de valor, baseados na relação imaginária que fazem da posição sujeito do referido menino.

Comentário 1 - Prestar queixa é o caralho. O Moleque é bandido? Quem foi prestar queixa deve se também.

Comentário 2 - Que horror, o preço tá muito barato. um menorzinho desse dá bem mais lucro, e eu acho que nem tá cadastrado em nenhuma facção do RJ, da pra usar no PCC de SP.

Comentário 3 - Aceita ticket ou vale transporte ...???

Comentário 4 - vai condenar quem, que fez a publicação ou quem deixou esse muleque chegar nesta situação, tá na cara, deve se indignar com esse estado de coisas, a publicação pode até despertar pais e autoridades.

Comentário 5 - Quem você ajuda primeiro? Seu filho com um arranhão no dedo ou esse moleque com um tiro na testa?

Comentário 6 - Uma alma sebosa dessa devia ta era morto... 
Raquel Costa Guimarães Nascimento; Antônio Fernandes Júnior. Discurso, história e memória a partir do post "vende-se um filhote de bandido".

O comentário 1 afirma que o menino é sim um bandido, e o 2 reitera a possibilidade de "usar" para um lucro ainda maior, pelo fato de "não estar cadastrado". Repete-se o discurso que, ora vincula o menino ao crime, ora vincula a um produto, visto que a palavra "cadastramento" pode estar vinculada a certo tipo de ligação entre prestadores de serviço ou a cadastro de mercadorias. O comentário 3 é um exemplo de comentários feitos na página do jornal que denunciava o "horror" da postagem, mas, ainda assim, em tom de brincadeira, demonstravam interesse em adquirir o "produto". No comentário 4, a "situação" do sujeito da foto é alvo de críticas aos pais e sociedade apenas pelos indícios deixados pela imagem, sem que, como dito, informação alguma sobre a criança, além da imagem fosse dada. Os comentários 5 e 6 revelam discurso agressivo, de julgamento e de desejo de limpeza social. A comparação feita entre "seu filho" e "esse moleque" demonstra o distanciamento social e afetivo, marcada pela ideologia presente na sociedade brasileira, conforme apontado nas elucidações acima. Nota-se que as características físicas apresentadas na imagem e a palavra "bandido", usada na postagem, foram as únicas referências, que, intercruzadas com esse imaginário, produziram esses discursos que delimitam e estabelecem o lugar social do sujeito da foto.

\section{Palavras finais}

A postagem "vende-se um filhote de bandido" aciona discursos do período escravagista brasileiro em que corpos negros eram comercializados como mercadoria. Notamos também o entrecruzamento de discursos relativos a investimentos financeiros atuais em que o sujeito da postagem é tratado como objeto ou como um animal. A associação do negro ao bandido e fora da lei é algo histórico no Brasil, reflexo de uma ideologia que o coloca em lugar de desigualdade histórica, reforçado por estereótipos fixados na mídia, escola e imaginário social, que ainda não foram vencidos nos âmbitos práticos da sociedade. Cultivou-se a ideia de que o negro é um criminoso em potencial, desse modo, um risco o qual se deve temer e repelir. Nota-se, ainda, sobre o negro em questão, que, ainda que seja uma criança, seu comportamento já seria determinado, para vadiagem ou criminalidade, haja vista sua cor e seus traços. Um menino, com as características interpretadas pela ideologia vigente como perigosas, não poderia ter outro destino, a não ser o crime. Aos sujeitos que produziram o discurso, caberia se aproveitar das vantagens de se ter um "filhote de bandido" à mão - 
quase um animal a se domesticar e tirar vantagem -, rir, como modo de demonstrar superioridade ou demonstrar desprezo e antipatia.

As observações feitas neste estudo podem ser aprofundadas posteriormente, alçando novas análises, traçando outros paralelos. Outros pontos sob os quais não dedicamos aplicação intensa ainda podem ser alvo de novas conjecturas. Sabemos também que o olhar do analista já define seu posicionamento e suas escolhas, interferindo, mesmo que minimamente, no traçado argumentativo, ainda que se intente distanciamento. Assim, outros conceitos podem ser aplicados e outros olhares podem perceber nuances não esboçadas por nós nesse trajeto. Consideramos, assim, este momentoda análise finalizada, mas com possibilidadesde novas aberturas e novas análises conforme a disponibilidade e o desejo dos autores ou de pesquisadores da área.

\section{Referências}

AGUIAR, Plínio. Racismo: estudante da FGV-SP é chamado de "escravo" por colega. 09 mar. 2018. Notícias R7. Disponível em: <https://noticias.r7.com/sao-paulo/racismoestudante-da-fgv-sp-e-chamado-de-escravo-por-colega-09032018> . Acesso em: 12 out. 2019.

ALMEIDA, Sílvio Luiz de. O que é racismo estrutural? Belo Horizonte: Letramento, 2018.

ALTHUSSER, Louis. Ideologia e aparelhos ideológicos de Estado. 3 ed. Lisboa: Editorial Presença/Martins Fontes, 1980.

BAKHTIN, Mikhail. Estética da criação verbal. 2 ed. São Paulo: Martins Fontes, 1997.

COURTINE, Jean-Jacques. O conceito de formação discursiva. In: Análise do discurso político: o discurso comunista endereçado aos cristãos. São Carlos: EdUFSCar, 2009.

FREYRE, Gilberto. Os escravos nos anúncios de jornais brasileiros do século XIX. São Paulo: Global, 2015.

FIORIN, José Luiz. Linguagem e Ideologia. São Paulo: Ática, 2003.

FOLHA de São Paulo. Racismo cordial. 25 jun. 1995. Caderno especial, p. 2-16. Disponível em:

<http://almanaque.folha.uol.com.br/racismocordial.htmhttps://acervo.folha.com.br/leitor.do?n umero=12830\&anchor $=505634 \&$ origem $=$ busca $\& p d=b 7 e 571$ b580dbe7a9bf8e6144cfec $3 \mathrm{~d} 1 \mathrm{c}>$. Acesso em: 12 out. 2018.

FONSECA, José Dagoberto. Você conhece aquela? A piada, o riso e o racismo à brasileira. São Paulo: Selo Negro, 2012. 
GOIS, Ancelmo. Publicitário publica em rede social foto de menor e diz: 'Vendo filhote de bandido'. O Globo, 23 dez. 2016. Disponível em: $<$ https://blogs.oglobo.globo.com/ancelmo/post/publicitario-publica-em-rede-social-foto-demenor-e-diz-vendo-filhote-de-bandido.html>. Acesso em: 10 set. 2019.

ORLANDI, Eni Puccinelli. Análise de discurso. In: ORLANDI, Eni Puccinelli; LAGAZZIRODRIGUES, Suzy (Orgs.). Discurso e textualidade. Campinas: Pontes, 2006, p. 11- 31.

ORLANDI, Eni Puccinelli. Educação em direitos humano: um discurso. In: Discurso em análise: sujeito, sentido e ideologia. Campinas: Pontes, 2012, p. 151-168.

ORLANDI, Eni Puccinelli. Análise de discurso: princípios e procedimentos. Campinas: Pontes, 2015.

MARCUSCHI, Luiz Antônio. Gêneros textuais emergentes no contexto da tecnologia digital. In: MARCUSCHI, Luiz Antônio; XAVIER, Antonio Carlos (Orgs.). Hipertexto e Gêneros Digitais: novas formas de construção do sentido. 2 ed. Rio de Janeiro: Lucerna, 2005.

MIELK, Ana Claudia. Negros e mídias: invisibilidades. Le Monde Diplomatique Brasil, São Paulo, jan. 2017. Ser negro no Brasil, p. 7-8.

NASCIMENTO, Raquel Costa Guimarães, RIBEIRO, Erislane Rodrigues. Uma análise discursiva dos memes "nego isso, nego aquilo". Revista do SELL - Estudos Linguísticos e Literários, v. 7, n. 1, 2018.

PÊCHEUX, Michel. Língua, linguagens, discurso. In: PIOVEZANI, Carlos; SARGENTINI, Vanice (Orgs.). Legados de Michel Pêcheux: inéditos em análise do discurso. São Paulo: Contexto, 2011, p. 63-75.

ROBERTS, Adam. SF and race. In: Scienc Fiction. Canadá: Routledge, p. 94 -106.

Recebido em: 28 de outubro de 2019

Aceito em: 2 de dezembro de 2019 